\title{
SEGMENTACIÓN EN EL INGRESO POR TRABAJO SEGÚN CONDICIÓN MIGRATORIA, GÉNERO Y ASCENDENCIA ÉTNICO-RACIAL EN URUGUAY ${ }^{\star}$ \\ LABOUR INCOME SEGMENTATION BY MIGRATION STATUS, GENDER, RACE AND ETHNICITY IN URUGUAY
}

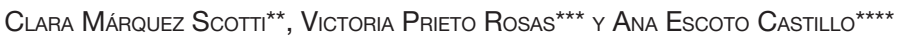

Resumen: La incorporación de los inmigrantes recientes en el mercado de trabajo uruguayo se ha caracterizado por una mayor concentración en ocupaciones de media y alta calificación, con importante incidencia de la sobreeducación. Este proceso ocurre en un mercado de trabajo ya segmentado por distintos ejes de desigualdad por clase ocupacional, género y ascendencia étnico-racial. Este artículo examina si la condición migratoria introduce un nuevo eje de segmentación. Los resultados derivados del análisis de los ingresos por trabajo con base en la Encuesta Continua de Hogares del período 2013-2017, muestran que efectivamente esto es así. La condición migratoria y la duración de la estancia en Uruguay se entrelazan con otras capas de segmentación del mercado laboral uruguayo, pero de manera variable a lo largo de la distribución del ingreso.

* El presente artículo fue desarrollado en el marco de la investigación "Inclusión de inmigrantes extranjeros en el mercado de trabajo uruguayo" financiada por la Agencia Nacional de Investigación e Innovación (ININ_1_2017_1_136263).

** Departamento de Trabajo Social, Facultad de Ciencias Sociales, Universidad de la República.

*** Programa de Población, Facultad de Ciencias Sociales, Universidad de la República.

**** Centro de Estudios Teóricos y Multidisciplinarios en Ciencias Sociales, Facultad de Políticas y Sociales, Universidad Nacional Autónoma de México. 
Palabras claves: migración sur-sur; inmigración; ascendencia étnico racial; brecha de ingreso; Uruguay.

Abstract: The incorporation of recent immigrants into the Uruguayan labour market has shown a greater concentration in medium and high skilled occupations, with an important incidence of over-education. This process occurs in a labour market already segmented by different inequalities by occupational class, gender and race. This article examines whether the migration status introduces a new layer of segmentation. The results, based on estimations on labour income using the Continuous Household Survey for the period 2013-2017, point in this direction. The migration status and length of stay in Uruguay are intertwined with other layers of segmentation from the Uruguayan labour market, but in a variable manner throughout the distribution of income.

Key words: south-south migration; immigration; race and ethnicity; income gap; Uruguay.

\section{INTRODUCCIÓN}

Los estudios acerca del tipo de inserción laboral y de las dinámicas de segmentación a las que se ven sujetos los migrantes son sumamente comunes en la literatura. Dentro de los corredores migratorios que involucran a los latinoamericanos, los análisis sobre las condiciones laborales en los principales países de acogida de la migración extrarregional —-tales como España y Estados Unidosse ha constatado que la mayoría de los trabajadores de este origen se insertan en el sector secundario de las economías segmentadas, sector caracterizado por la precariedad laboral, la baja calificación, y con ello, el bajo ingreso ${ }^{1}$.

Ahora bien, en los últimos años asistimos a un proceso de diversificación e intensificación de la migración intrarregional en Améri-

1 Para el contexto de acogida español véase Bernardi, Garrido y Miyar (2011); Aysa-Lastra y Cachón (2013); Muñoz Comet, (2013); Rodríguez-Planas y Nollenberger (2016) y para el estadounidense véase Caicedo (2015); Gandini y Lozano-Ascencio, (2015), entre otros. 
ca Latina. Los datos de la última ronda censal indican que en 2010 el $63 \%$ de la migración internacional de latinoamericanos corresponde a la migración dentro de la región (Martínez y Orrego, 2016). Teniendo en cuenta que los mercados de trabajo latinoamericanos están signados por la pervivencia de dinámicas de inclusión y exclusión laboral (Pérez Sáinz y Mora Salas, 2008) que históricamente han generado inserciones laborales heterogéneas, cabe preguntarse si se encuentran en ellos segmentaciones laborales similares a las encontradas en las dinámicas migratorias sur-norte. Más específicamente, es importante indagar en qué medida la condición de inmigrante suma una nueva desventaja en mercados de trabajo caracterizados por la generación de un excedente estructural de mano de obra.

El análisis del ingreso por trabajo es una de las dimensiones ampliamente reconocidas para el estudio de las condiciones laborales (Mora Salas, 2010) y, también, es la dimensión que consideraremos en este artículo. Los antecedentes de estudios sobre brecha de ingresos por trabajo entre inmigrantes y nativos dentro del Cono Sur son poco comunes, aunque no inexistentes. En Argentina, los análisis de este tipo confirman las hipótesis de una desventaja de los inmigrantes sobre los nativos, a pesar de que existen algunos matices según el origen nacional y la metodología adoptada por los investigadores (Cerrutti y Maguid, 2006; Torres y Celton, 2009). En Brasil y Chile la evidencia contraviene las experiencias de Argentina y de los contextos de acogida extrarregionales. En el primero la brecha en los ingresos por trabajo es favorable a los extranjeros (Sala y Rios Neto, 2006), mientras en Chile no se encuentran diferencias significativas entre nativos e inmigrantes (Petitpas Brahm, 2017).

En este artículo se estudia el caso de Uruguay, donde el incremento reciente de la inmigración de origen caribeño ha traído aparejado la diversificación del perfil sociodemográfico de los trabajadores inmigrantes (OEA-SICREMI, 2017). A pesar de que los niveles de rechazo de la inmigración en la opinión publica uruguaya son los más bajos del concierto regional (Koolhaas, Prieto y Robaina, 2017), los antecedentes para este país indican que la condición de inmigrante reciente impacta negativamente en el acceso al empleo y positivamente en la prevalencia de sobreeducación, aunque los resultados no son concluyentes cuando se analiza su efecto sobre la probabilidad de estar desprotegido en el empleo (Prieto, Robaina y Koolhaas, 2016). A su vez, la sobreeducación se traduce en una penalización sobre el ingreso de los trabajadores inmigrantes (Mén- 
dez, 2018). Por otro lado, con independencia de la condición migratoria en el mercado laboral uruguayo persisten brechas salariales entre grupos según ascendencia étnico racial (Scuro Somma, 2008), género y sector de ocupación (Amarante y Espino, 2004; Borraz y Robano, 2010; Espino, 2013). Estos procesos que afectan, por un lado, específicamente al ingreso de los trabajadores inmigrantes y, por otro, a todos los trabajadores, no se han explorado de manera simultánea atendiendo a las diferencias en el ingreso según condición migratoria.

Nos proponemos analizar si se aprecian brechas en el ingreso por trabajo entre nativos e inmigrantes extranjeros en Uruguay y a quiénes afecta negativamente esta desigualdad. Considerando además que la inmigración extranjera se está transformando en Uruguay en cuanto al origen nacional y ascendencia étnico racial, es de particular interés saber si se observa una acumulación adicional de otros ejes de desigualdad. Particularmente, nos interesa conocer (i) si existe una brecha en el ingreso entre las personas migrantes y las nativas; (ii) si varía a lo largo de la distribución del ingreso; (iii) si la magnitud de la brecha según condición migratoria se reduce con el tiempo transcurrido desde la llegada a Uruguay; y (iv) si esta brecha es perceptible cuando se tienen en cuenta otras desigualdades por sexo y ascendencia étnico racial. Con el propósito de atender estas interrogantes utilizamos los microdatos de la Encuesta Continua de Hogares para los años 2013-2017 para estimar regresiones por mínimos cuadrados ordinarios y regresiones cuantílicas sobre el ingreso percibido por la ocupación principal.

Este artículo aporta evidencia para las discusiones teóricas acerca de la vigencia de las teorías de mercados duales, asimilación y asimilación segmentada para describir los procesos de incorporación al mercado de trabajo de la inmigración en contextos de migración sur-sur. El caso uruguayo reúne algunas condiciones que lo vuelven interesante: se trata de un mercado de por sí segmentado por género, ascendencia étnico-racial y sectores de actividad, y destaca en Latinoamérica por la fortaleza de su institucionalidad laboral.

Siguiendo a esta introducción, en la segunda sección se presentan los antecedentes sobre inmigración y empleo del caso uruguayo. En la tercera sección se introducen los datos y metodología adoptadas. En la cuarta sección se presentan los principales resultados y, por último, la quinta sección incluye las principales conclusiones. 


\section{INMIGRACIÓN Y DESIGUALDADES EN LOS INGRESOS}

La literatura sobre inmigración e inclusión social ha acumulado suficiente evidencia para sostener que los inmigrantes ganan menos que los nativos no migrantes en los primeros años de residencia en un nuevo país y que, a medida que transcurre el tiempo su ingreso tiende a crecer (Lubotsky, 2007). Entre los factores que explican las diferencias en la velocidad con que ocurre esta convergencia a lo largo del tiempo se incluyen el efecto del año o cohorte de entrada al país de acogida (Lubotsky, 2007; Villarreal y Tamborini, 2018), las habilidades de los inmigrantes (entre ellas los idiomas), el estatus documental, el país de nacimiento, el grupo étnico-racial, y el sexo del migrante (Adsera y Chiswick, 2007).

Desde los enfoques que ponen el acento en el análisis de trayectorias intra-grupos -más que en la convergencia entre nativos e inmigrantes - Fellini y Guetto (2019), analizan las trayectorias laborales entre los contextos de salida y llegada atendiendo al estatus de las ocupaciones. Sus resultados sugieren que en mercados laborales segmentados como los de España, Italia o Francia, las trayectorias laborales de los inmigrantes no siguen la forma de " $U$ " encontrada en los mercados laborales de acogida anglosajones más desregulados. En cambio, la recuperación posterior a la caída inicial de estatus e ingreso - que ocurre entre el último trabajo en origen y el primero en destino- es menos pronunciada. Las autoras identifican que la transferibilidad de credenciales educativas incide positivamente y contribuye a mejorar la movilidad ocupacional en estos contextos. En este sentido, desde la teoría del capital humano, se entiende que la formación y adquisición de habilidades y experiencias en el país de acogida es un trampolín hacia la paridad de ingresos. En cambio, la teoría de la segmentación laboral sostiene que hay rigideces que no se superan por este camino. Por ejemplo, el tipo de documentación también determina las posibilidades de adquirir formación y experiencia laboral en el país de inmigración $\mathrm{y}$, por ende, eventualmente puede cercenar las oportunidades de mejorar el ingreso.

Dentro del conjunto de los aspectos que representan rigideces, no necesariamente salvables desde la adquisición de capital humano en el país de acogida, la perspectiva de la segmentación laboral añade la incidencia del género y la ascendencia étnico racial como ejes que estructuran desigualdades dentro del mercado laboral. 
Anderson (2015) concluye que los inmigrantes que comparten rasgos étnico-raciales con la población nativa, o que dominan de antemano el idioma de ese país, están expuestos a niveles de disparidad salarial menores, y alcanzan la convergencia antes que los inmigrantes de origen étnico-racial minoritario o que quienes no manejan el idioma (Kaas y Manger, 2010; Arceo Gómez y Campos Vázquez, 2014). Villarreal y Tamborini (2018) analizan el caso de Estados Unidos y encuentran distintas trayectorias de asimilación de ingresos según grupo étnico-racial. Los inmigrantes negros e hispanos no logran alcanzar el nivel de ingreso de la población nativa blanca —como sí ocurre con los inmigrantes blancos y asiáticos-. El análisis longitudinal que realizan estos autores señala que, si bien el ingreso de los hispanos y los inmigrantes afrodescendientes no se asimila al de nativos, estos grupos sí experimentan mejoras relativas respecto a sí mismos y alcanzan la paridad de ganancias con los nativos de igual ascendencia étnico racial.

Uno de los conceptos referidos en la literatura de migración y trabajo para el análisis de estos fenómenos es el de discriminación. Ahora bien, cuando hay diversos factores de discriminación que confluyen en una misma persona se genera un nuevo fenómeno. De acuerdo a Valles, Cea D’Ancona y Dominguez (2017) el término más arraigado en la literatura académica para referirse a este fenómeno es el de discriminación interseccional. Aquí entenderemos que la discriminación intereseccional es uno de los mecanismos que está detrás de la acumulación de ventajas y desventajas y de las desigualdades de acceso al trabajo y al empleo de calidad.

\subsection{Inmigración y brechas salariales en el Cono Sur}

Si bien en Uruguay aún no se han analizado las brechas de ingresos entre inmigrantes extranjeros y nativos, en el resto de los países del Cono Sur existen antecedentes, que en su mayoría utilizan métodos de descomposición. Cerrutti y Maguid (2006) analizaron la brecha de ingresos para el Gran Buenos Aires, entre el conjunto de inmigrantes procedentes de Chile, Bolivia, Paraguay, Brasil, Uruguay y Perú. Encuentran que una porción de la brecha en el ingreso no se explica por las características individuales observables, sino por el conjunto de características no especificadas, entre las que pueden incluirse efectos de selección y discriminación. Esa porción de la desigualdad de ingreso que no explican las características observables 
es menor entre las mujeres que entre los varones, y entre los trabajadores menos educados que ocupan puestos de baja calificación que entre los trabajadores calificados. En cambio, Torres y Celton (2009) encuentran que la brecha salarial entre paraguayos y argentinos es más amplia entre las mujeres y que la porción de este diferencial atribuible a la discriminación también es mayor entre ellas.

La evidencia sobre brechas en el ingreso laboral entre nativos e inmigrantes para el resto de los países de acogida del Cono Sur va en sentido contrario. Por un lado, Petitpas Brahm (2017) analiza la evolución de los salarios de los migrantes internacionales teniendo en cuenta las cohortes de llegada a Chile. Sus estimaciones señalan la ausencia de diferencias significativas en los salarios de inmigrantes y chilenos. Por otro lado, en el caso brasileño el salario medio de los inmigrantes supera al de los trabajadores nativos (Sala y Rios Neto, 2006). En los casos de Chile y Brasil, los investigadores concluyen que la evidencia debe interpretarse teniendo en cuenta que la inmigración regional recibida por estos países tiene un nivel de calificación muy superior al del promedio de su población. En ambos mercados laborales se valoran más los atributos productivos de trabajadores extranjeros que de nativos (Sala y Rios Neto 2006).

\subsection{Inmigración, trabajo y brechas del ingreso laboral en Uruguay}

Si bien no hay evidencia que recoja el efecto conjunto de la condición migratoria, el género y la ascendencia étnico racial para Uruguay, hay una serie de antecedentes sobre la incorporación al mercado de trabajo uruguayo de los inmigrantes recientes, donde se constatan comportamientos diferenciales según sexo. Por otro lado, es abundante la literatura sobre las desigualdades del mercado de trabajo uruguayo por sexo, ascendencia étnico racial y sectores de ocupación para el total de la población.

La evidencia que analiza el desempleo y la sobreeducación según condición migratoria arroja que a medida que se incrementa el tiempo transcurrido en Uruguay, las diferencias entre nativos y retornados o extranjeros disminuyen, aunque esta reducción no es tan marcada entre los segundos (Prieto et al., 2016). Las mujeres inmigrantes tienen menores probabilidades de acceder al empleo que los varones de este grupo (Prieto et al., 2016). En un análisis que se 
limita a la población inmigrada, Méndez (2018) encuentra que entre las mujeres inmigrantes se reduce la probabilidad de sobreeducación a medida que se incrementa el tiempo de residencia en Uruguay y la experiencia en el mercado de trabajo. A su vez, la sobreeducación penaliza los ingresos salariales de los inmigrantes, pero también este efecto varía según sexo siendo mayor entre los varones.

Se cuenta con suficientes antecedentes sobre la existencia de brechas en la remuneración de los trabajadores asalariados que se agudizan para ciertas conjugaciones de género, sector de ocupación y ascendencia étnico racial en Uruguay (Amarante y Espino, 2004; Bucheli y Porzecanski, 2008; Borraz y Robano, 2010; Bucheli y Sanromán, 2010). Hacia finales de los noventa se corroboró una reducción sustantiva de la diferencia salarial entre varones y mujeres con iguales características (Rivas y Rossi, 2000). Más tarde Borraz y Robano (2010) corroboran un nuevo incremento de esta brecha en la primera década de este milenio fundamentalmente en los quintiles más altos de la distribución salarial ("techo de cristal"), resultado que con anterioridad advierten Bucheli y Sanromán (2005). En este período la mayor parte de la diferencia se explica por un efecto de discriminación. A ello debe sumarse el efecto de la segregación ocupacional que es uno de los factores que contribuye a mantener las desigualdades de género y las diferencias salariales en el trabajo (Amarante y Espino, 2004).

Además, la discriminación racial explica una porción importante de la brecha salarial que separa a la población afrodescendiente de la población blanca y su efecto es mayor entre los varones. Los resultados derivados del análisis de descomposición realizado por Bucheli y Porzecanski (2008) indican que los trabajadores afrodescendientes tienen menores probabilidades de acceder a las ocupaciones mejor remuneradas incluso teniendo el mismo nivel educativo y experiencia laboral que los blancos. Bucheli y Sanroman (2010) también encuentran una brecha desfavorable hacia los afrodescendientes que además persiste a lo largo de toda la distribución del ingreso.

Con base en la literatura internacional y nacional se espera que, en el caso uruguayo, donde ya existen rígidas brechas salariales por género, sector de ocupación y ascendencia étnico racial, la condición migratoria sume otra capa de fragmentación y que éstas actúen de forma simultánea perjudicando principalmente a quienes reúnen más de una condición minoritaria. También presumimos que el tiempo de asentamiento y los niveles de ingreso introduzcan diferencias significativas en la acumulación de estas desigualdades. 


\section{DATOS, VARIABLES Y MÉTODOS}

En este artículo estudiamos los ingresos laborales de la ocupación principal con base en microdatos de la Encuesta Continua de Hogares del período 2013-2017. Se incluyen en el análisis tanto a los trabajadores dependientes como a los independientes puesto que los modelos se estiman sobre el ingreso por trabajo y no sobre el salario. Se modela el logaritmo natural del ingreso laboral por hora trabajada en la ocupación principal con estimaciones paramétricas y no paramétricas. De este modo, intentamos lidiar con la heterogeneidad de la distribución del ingreso propia de un ámbito desigual como el latinoamericano.

Construimos la variable estatus migratorio que considera el tiempo de asentamiento en el país. Esta variable categórica consta de tres grupos: (1) nativos; (2) inmigrantes recientes (con cinco años o menos en el país); (3) inmigrantes antiguos (con más de cinco años en el país). La variable sexo adopta los valores (1) varón y (2) mujer. Por último, la variable autoidentificación étnico-racial tiene los valores: (1) blanca, (2) afrodescendiente y (3) otra. Además, en los modelos se incluyen una serie de controles: sociodemográficos, características del empleo, cargas familiares del hogar y espacio de residencia rural o urbana.

En primer lugar, se realiza un análisis bivariado para presentar algunas características sociodemográficas y de la ocupación principal de los tres grupos poblacionales de interés. Además, presentamos las distribuciones no paramétricas (distribuciones Kernel) del logaritmo natural del ingreso laboral por hora de la ocupación principal para aproximarnos a las diferencias en los ingresos a lo largo de la distribución según la condición migratoria.

Como es sabido, al modelar la inserción laboral se cuenta con una serie de sesgos de selección que presentan desafíos para las estimaciones e interpretaciones de los resultados. Para dar cuenta del sesgo de quienes se insertan en el empleo, el análisis multivariado comienza con un modelo logístico binomial de acceso a la ocupación. Esto nos dará información acerca del tipo y magnitud del sesgo presente en las siguientes estimaciones. Los regresores incluidos en este modelo consideran las tres variables explicativas (estatus migratorio, sexo y autoadscripción racial) y variables de control sociodemográficas (edad y años de educación aprobados), del hogar (parentesco con el jefe de hogar, condición de unido y tasa de 
dependencia intrafamiliar $)^{2}$, residencia urbana o rural y año de la encuesta.

En tercer lugar, ajustamos ecuaciones de ingreso utilizando Mínimos Cuadrados Ordinarios (MCO), incluyendo las tres variables de interés dentro de los regresores, y controlando por otros aspectos críticos de la segmentación salarial del mercado laboral uruguayo. Allí se estima el valor medio de la variable dependiente. Tratándose de ingresos del trabajo, esta estimación oculta las asociaciones diferenciales entre las variables a lo largo de la distribución del ingreso.

Por último, y atendiendo a la limitación del MCO recién mencionada, se estiman regresiones cuantílicas para los percentiles 10, 50 y 90 , i.e. se obtienen estimaciones (vectores) diferentes para cada uno de éstos. En este caso los errores estándar se estiman mediante simulaciones (bootstrap standard errors).

Tanto en los modelos estimados utilizando MCO como en las regresiones cuantílicas se incluyen interacciones entre la condición migratoria, el sexo y la ascendencia étnico racial.

\subsection{Limitaciones}

Este análisis cuenta con una serie de limitaciones que afectan fuertemente las inferencias realizadas a partir de los datos disponibles. En primer lugar, la fuente de datos utilizada subestima a la población inmigrada en condiciones de vulnerabilidad socioeconómica. De acuerdo con resultados preliminares de la Etnoencuesta de Inmigración Reciente para la Ciudad de Montevideo (2018) una proporción destacada de los inmigrantes que llevan menos tiempo de residencia en Uruguay y tienen bajos ingresos residen en viviendas colectivas, como pensiones y residencias, que no forman parte del marco muestral de la Encuesta Continua de Hogares. Es decir, es razonable pensar que los datos aquí analizados (que son los únicos disponibles por el momento) muestran un panorama más favorable que el realmente existente.

En segundo lugar, los expansores poblacionales de la ECH a partir de 2013 se sustentan en las proyecciones de población realizadas

2 Las variables de control relativas al hogar se integran en el supuesto de que la participación laboral está mediada por las características del hogar. 
por el INE con base en los datos del Censo de Población (2011) bajo el supuesto de saldo migratorio nulo. La evolución del saldo migratorio de entradas y salidas por puestos fronterizos entre 2012 y 2017 indica un saldo favorable a la inmigración extranjera.

Los dos elementos hasta aquí mencionados exigen tener en cuenta que los resultados presentados podrían subestimar la magnitud de las brechas por ingresos laborales.

En tercer lugar, nuestras inferencias están afectadas por un efecto de selección dentro del grupo de inmigrantes más antiguos. Lógicamente en este grupo no se encuentran aquellos que tras pasar un tiempo en el país lo abandonan. Dependiendo de si las salidas están protagonizadas por los inmigrantes con mejores o peores desempeños, la composición del grupo de quienes permanecen por más tiempo en el país estará sesgada positivamente o negativamente.

\section{RESULTADOS}

\subsection{Características sociodemográficas y de la inserción laboral}

La composición por sexos de nativos e inmigrante recientes no difiere significativamente e indica una relación de sexos equilibrada en ambos grupos (Tabla 1). En cambio, en el grupo poblacional de inmigrantes con más de cinco años de residencia en Uruguay y una estructura de edades más envejecida, predominan las mujeres. De hecho, la edad promedio de este último grupo es la mayor (38 años), y son los inmigrantes recientes quienes muestran una estructura de edades más joven (33,5 años) y menos feminizada. De todos modos, otras fuentes de datos sugieren que, para algunos de los orígenes de la inmigración reciente, tales como Colombia, Perú, República Dominicana y Paraguay sí habría mayor proporción de mujeres, lo que va en consonancia con las tendencias regionales (MIDES, 2017). Un rasgo sobresaliente entre los inmigrantes recientes es la mayor prevalencia de minorías étnicas afrodescendientes $(13,9 \%)$ e indígenas $(9,8 \%)$ (Tabla 1$)$. Al predominio de minorías étnico-raciales y edades más jóvenes, se suma un mayor promedio de años de estudio $(13,3)$ que supera en más de tres años al de la población nativa y en dos al grupo de inmigrantes más antiguos. 
TABLA 1

\section{CARACTERÍSTICAS POBLACIONALES Y DE LA OCUPACIÓN PRINCIPAL POR ESTATUS MIGRATORIO. URUGUAY, 2017}

Población de 14 a 64 años

\begin{tabular}{|c|c|c|c|}
\hline & Nativo* $^{*}$ & $\begin{array}{l}\text { Inmigrante reciente } \\
\text { (hasta } 5 \text { años) }\end{array}$ & $\begin{array}{l}\text { Inmigrante antiguo } \\
\text { (más de } 5 \text { años) }\end{array}$ \\
\hline Mujer (\%) & $50,6(0,01)$ & $49,3(0,09)$ & $53,2(0,07)$ \\
\hline Edad en años (promedio) & 37,1 & 33,5 & 38,0 \\
\hline \multicolumn{4}{|l|}{ Ascendencia étnico racial (principal) (\%) } \\
\hline Blanca & 94,1 & 76,1 & 90,5 \\
\hline Afro & 4,4 & 13,9 & 4,3 \\
\hline Indígena & 1,5 & 9,8 & 4,4 \\
\hline Otra & 0,1 & 0,3 & 0,8 \\
\hline Años de educación (promedio) & $10,0(0,00)$ & $13,3(0,03)$ & $11,4(0,02)$ \\
\hline Residencia urbana (\%) & 83,5 & 89,2 & 88,0 \\
\hline Tasa de actividad & 73,0 & 79,4 & 77,6 \\
\hline Tasa de ocupación & 67,0 & 68,3 & 73,2 \\
\hline Tasa de desempleo abierto & 8,1 & 13,9 & 5,7 \\
\hline Total (100\%) & 2.290 .450 & 14.797 & 38.321 \\
\hline \multicolumn{4}{|l|}{ Población ocupada (ocupación principal) } \\
\hline Mujer (\%) & 44,9 & 40,4 & 46,4 \\
\hline Asalariados privados (\%) & 56,6 & 76,5 & 61,2 \\
\hline No realiza aportes jubilatorios (\%) & 24,7 & 23,8 & 24,7 \\
\hline Jornada laboral semanales (promedio) & $37,6(0,01)$ & $40,7(0,13)$ & $37,3(0,08)$ \\
\hline Subempleo (\%) & 8,4 & 6,5 & 6,5 \\
\hline Años en el empleo actual (promedio) & $8,8(0,01)$ & $2,4(0,04)$ & $7,6(0,06)$ \\
\hline \multicolumn{4}{|l|}{ Clase ocupacional (\%) } \\
\hline No manual de alta calificación & 21,9 & 37,1 & 31,5 \\
\hline No manual de baja calificación & 33,2 & 35,8 & $35 ., 2$ \\
\hline Manual calificada & 25,7 & 13,1 & 19,5 \\
\hline Ocupaciones elementales & 18,5 & 14,1 & 13,8 \\
\hline Fuerzas Armadas & 0,6 & 0,0 & 0,0 \\
\hline \multicolumn{4}{|l|}{ Sector de actividad } \\
\hline Primario & 9,0 & 3,6 & 7,1 \\
\hline Secundario & 19,6 & 18,1 & 18,5 \\
\hline Terciario & 71,4 & 78,3 & 74,4 \\
\hline Tercerización en todos los trabajadores (\%) & 2,8 & 6,0 & 2,3 \\
\hline Total & 1.604 .407 & 10.240 & 30.042 \\
\hline
\end{tabular}

${ }^{\star}$ ) Nota: la categoría de nativos incluye a las personas nacidas en Uruguay con (retornados) y sin experiencia migratoria internacional.

Fuente: elaboración propia con base en microdatos de la Encuesta Continua de Hogares del 2017. 
Asimismo, los grupos poblacionales de inmigrantes recientes y antiguos muestran una mayor concentración residencial en áreas urbanas respecto a los nativos. Casi nueve de cada diez inmigrantes residen en áreas urbanas (Tabla 1).

La tasa de actividad de los inmigrantes recientes es también la más alta, situándose casi seis puntos porcentuales por encima de la población nativa y casi dos puntos por encima de la participación de los inmigrantes antiguos (Tabla 1). Sin embargo, los altos niveles de actividad de los inmigrantes recientes no se traducen necesariamente en una mayor tasa de ocupación porque aún es relativamente elevada la incidencia del desempleo abierto en este grupo (13,9\%). En cambio, entre los inmigrantes antiguos donde también es alta la tasa de actividad, encontramos valores máximos y mínimos de la ocupación y el desempleo respectivamente. En síntesis, si bien ambos grupos de inmigrantes tienen una fuerte participación en el mercado de trabajo, aquellos con más años de asentamiento en el país han conseguido una mayor incorporación al trabajo. Puede interpretarse que transcurrido cierto tiempo de asentamiento disminuye el riesgo a estar en desempleo, o bien quienes permanecen en el país - no retornan ni reemigran- son aquellos que han tenido mejores y mayores oportunidades de acceso al empleo.

También en la Tabla 1 se incluye información sobre las características de la ocupación principal de la población de 14 años y más. En este grupo hay un claro predominio masculino especialmente pronunciado entre los inmigrantes recientes (apenas el 40,4\% son mujeres). En cuanto a las características promedio del empleo, los inmigrantes recientes están sobrerrepresentados en el sector privado asalariado, tienen en promedio una jornada laboral semanal apenas más extensa que la de los nativos o los inmigrantes antiguos, tienen menos antigüedad en el empleo (2,4 años), y tienden a concentrarse en las ocupaciones no manuales de alta calificación. El nivel de desregulación laboral (empleo sin aportes jubilatorios) es alto, aunque similar al del resto de los ocupados. El subempleo ${ }^{3}$ afecta a los inmigrantes recientes de forma casi semejante a la de los nativos o a quienes llevan más tiempo en Uruguay. El sector terciario de

3 Hemos tomado la definición usual de subempleo por hora que identifica a los ocupados que «trabajan menos de 40 horas, desean trabajar más horas, están disponibles para trabajar más horas, pero no consiguen más trabajo» (INE, 2015, p. 1). 
actividad es el principal empleador en Uruguay, y la participación en este sector está sobre representada dentro de los trabajadores inmigrantes recientes. Asimismo, la incidencia de la tercerización para los trabajadores inmigrantes es mayor entre los más recientes.

Con relación a los ingresos percibidos en la ocupación principal según el estatus migratorio, la Tabla 2 muestra que, en promedio, los inmigrantes recientes perciben mayores ingresos que los inmigrantes con mayor tiempo en el país y que los nativos. Ahora bien, los valores de la mediana similares en los tres casos y la alta desviación estándar especialmente marcada para los inmigrantes recientes muestran un panorama distinto. Los inmigrantes con menor tiempo de asentamiento ostentan la distribución de ingresos más desigual; con alta concentración de ingresos en los deciles más altos, pero también en los deciles bajos. Estos datos de ingreso muestran que dentro de este grupo también conviven situaciones laborales muy disímiles.

TABLA 2

INGRESO EN LA OCUPACIÓN PRINCIPAL DE LOS OCUPADOS POR CONDICIÓN MIGRATORIA (EUROS). URUGUAY, 2017

\begin{tabular}{|c|c|c|c|}
\hline & Nativos & Inmigrante reciente & Inmigrante antiguo \\
\hline Promedio de ingreso & 892,4 & $1.263,9$ & $1.063,8$ \\
\hline Mediana de ingreso & 706,8 & 729,4 & 735,2 \\
\hline Desviación estándar & $1.012,7$ & $1.828,4$ & $1.299,7$ \\
\hline
\end{tabular}

Nota: valores convertidos de peso uruguayo a euro con base en el promedio anual del valor de compraventa de 2017 (INE, 2019).

Fuente: elaboración propia con base en microdatos de la Encuesta Continua de Hogares del 2017.

En el Gráfico 1 se presenta la función de densidad del logaritmo natural del ingreso por hora proveniente de la ocupación principal por condición migratoria. El gráfico muestra las diferencias relativas en el ingreso a lo largo de toda la distribución, mostrando la heterogeneidad sugerida en los datos anteriores. Para los inmigrantes recientes, se observa una mayor concentración en el rango medio de ingresos (mayor altura de la curva), en comparación con los otros 
dos grupos. A su vez, a partir del rango medio, las curvas de densidad se observan más a la derecha para los inmigrantes antiguos y los nativos, lo que indica una brecha desfavorable para los inmigrantes recientes. En los rangos más altos del ingreso esta situación se revierte. Los inmigrantes, independientemente del tiempo de asentamiento, tienen una brecha de ingreso favorable con relación a los nativos.

\section{GRÁFICO 1}

DISTRIBUCIÓN KERNEL DEL LOGARITMO DEL INGRESO POR HORA EN LA OCUPACIÓN PRINCIPAL. URUGUAY, 2017

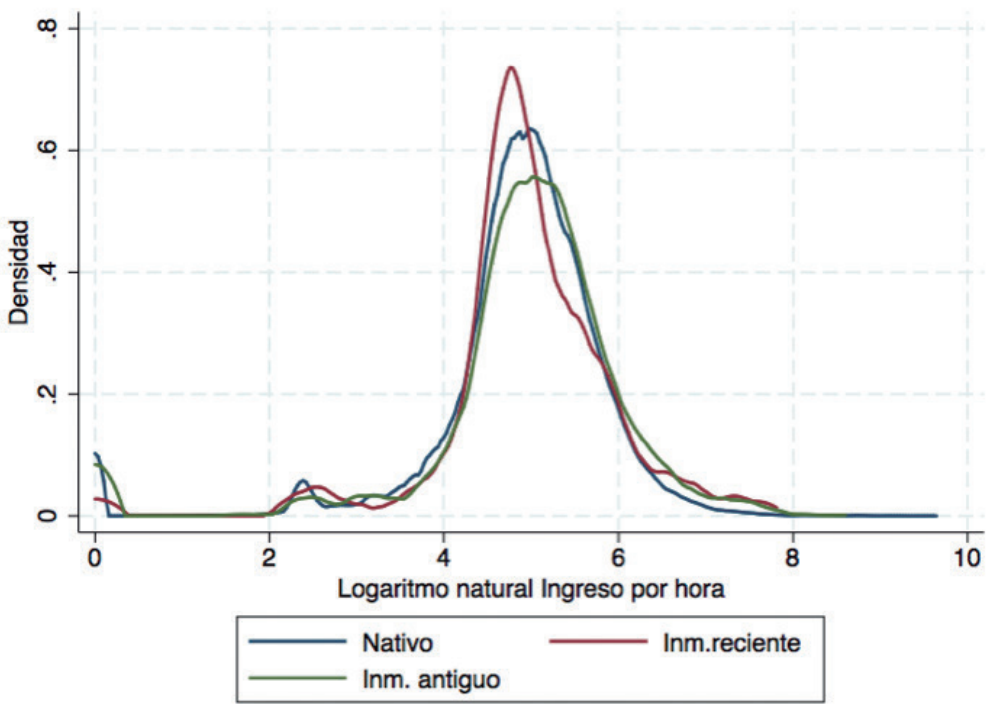

Fuente: elaboración propia con base en microdatos de la Encuesta Continua de Hogares del 2017.

En síntesis, los inmigrantes recientes que habitan viviendas particulares, en promedio, se caracterizan por tener mayores niveles de educación, ser más jóvenes, residir principalmente en áreas urbanas, mostrar altos niveles de actividad, pero con mayor desempleo. A su vez, dentro de este mismo grupo, los ocupados se caracterizan por emplearse en puestos que demandan más calificación, verse considerablemente afectados por la desregulación laboral, pero en 
grados semejantes al resto de los ocupados, tener menos antigüedad en el empleo, concentrarse en el sector terciario y estar más expuestos a la tercerización. Los datos de los ingresos por trabajo sugieren, a su vez, la existencia de remuneraciones laborales particularmente disímiles entre los inmigrantes recientes.

Estas características, para el promedio, muestran una segmentación laboral parcialmente distinta a la usualmente encontrada en los contextos de acogida propios de la migración sur-norte, típicamente caracterizados por la concentración de inmigrantes en un sector secundario del mercado de trabajo que concentra al empleo precario. Por un lado, los inmigrantes ocupados en Uruguay comparten con los inmigrantes de los contextos de acogida de migración sur-norte, la concentración en el sector terciario y estar más expuestos a la tercerización. Por otro lado, difieren de aquellos por su mayor concentración en puestos de alta calificación y porque la incidencia de la desregulación laboral no es sustantivamente distinta a la de los nativos. Esta última afecta a uno de cada cuatro trabajadores, siendo un rasgo estructural de los mercados de trabajo de la región y sus economías ${ }^{4}$. También es preciso tener en cuenta las características del flujo migratorio que recibe Uruguay, en promedio más calificado que la población nativa. Retomando a Sala y Rios Neto (2006) es posible que, para comprender este caso, convenga contemplar la posibilidad de que los atributos productivos de los extranjeros sean valorados - en promedio- tanto como o más que los de los trabajadores nativos.

\subsection{Sesgo de selección en la ocupación}

Si bien las estimaciones que interesan en este artículo son aquellas sobre la incidencia de la condición migratoria en el ingreso de la ocupación, es innegable que el acceso al empleo es un proceso selectivo y que dicha selectividad afecta las estimaciones ulteriores sobre las condiciones laborales y la remuneración. Por esta razón, el análisis multivariado comienza con un modelo logístico estimado para la probabilidad de estar ocupado (Tabla A1, en Anexo).

4 La incidencia del trabajo no regulado en Uruguay es notoriamente más baja que el promedio sudamericano (excluyendo a Brasil, Guyana Francesa, Venezuela y Surinam) próximo al 57\% (ILO, 2019). 
Los resultados indican que existe un sesgo de selección según el cual las mujeres tienen menores chances de estar ocupadas que los varones. Asimismo, los inmigrantes recientes presentan un 57\% menos de probabilidades de acceder al empleo respecto a los nativos. Contrario a lo esperado, el sesgo de selección por ascendencia étnico racial muestra resultados ambiguos. Por una parte, las personas con ascendencia afro no tienen una desventaja comparativa respecto a la de quienes se identifican como blancos para acceder al empleo, mientras que las personas pertenecientes a otras minorías étnicoraciales tienen un 6\% más de chances de acceder al empleo que los blancos.

Si bien a priori puede sorprender que la población afrodescendiente tenga mayor probabilidad de estar ocupada que la población autoidentificada como blanca, los antecedentes para el caso uruguayo ya han mostrado esta particularidad para este grupo. Se trata de una población demográficamente más joven, con mayores niveles de ocupación y mayores niveles de desempleo que la no afro (Cabella, Nathan y Tenenbaum, 2013); a ello se suma que su participación en el mercado de trabajo es mayor y más prolongada en el tiempo, aunque también el tipo de inserción que encuentran es de las más precarias en el mercado de empleo (Bucheli y Cabella, 2007).

\subsection{Análisis de los ingresos según condición migratoria, sexo y ascendencia étnico racial}

A partir de la estimación de varios modelos sobre el ingreso, buscamos conocer las diferencias en el ingreso según condición migratoria, sexo y ascendencia étnico racial principal. El Gráfico 2 muestra los efectos marginales sobre el logaritmo del ingreso por hora del trabajo principal del modelo por mínimos cuadrados ordinarios (Tabla A2, en Anexo) y de las estimaciones de las regresiones cuantílicas para los percentiles 10, 50 y 90 (Tabla A3, en Anexo). En la misma figura se incluyen estimaciones análogas para las que se incorporan interacciones de la condición migratoria con ascendencia étnico racial (Tabla A3, en Anexo). Las interacciones entre la condición migratoria y el sexo se incluyeron en los modelos estimados por MCO y como los efectos no resultaron significativos no se incluyeron de las estimaciones posteriores. 
GRÁFICO 2
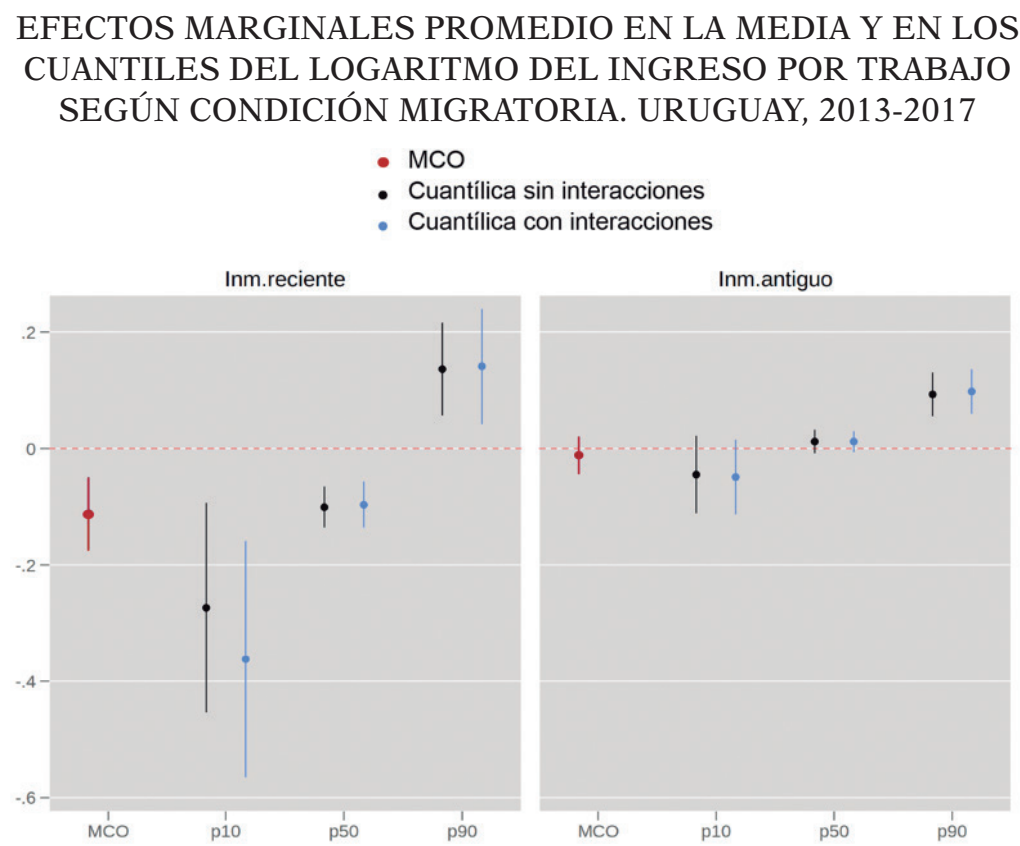

Nota: este gráfico surge de las estimaciones presentadas en la Tabla A3 en el Anexo.

Fuente: elaboración propia con base en microdatos de la Encuesta Continua de Hogares del 2013 al 2017.

Los resultados de la regresión lineal por MCO indican una desigualdad desfavorable para los inmigrantes recientes en comparación con los nativos cuyas remuneraciones son en promedio un 14\% menores. El coeficiente asociado a los inmigrantes con mayor tiempo de asentamiento no es estadísticamente significativo, sin embargo, se puede afirmar que la distancia que separa a los trabajadores nativos de los inmigrantes antiguos es menor que la observada entre nativos e inmigrantes recientes.

Ahora bien, los resultados derivados de las regresiones por MCO están estimados para los valores medios de las variables. No obstante, como lo muestra el Gráfico 2, dada la heterogeneidad en los ingresos la relación entre las variables cambia a lo largo de la distribución, lo que explica las diferencias en las estimaciones ob- 
servadas en función del percentil del que se trate. Las mismas son especialmente marcadas para los inmigrantes recientes. A partir de aquí el análisis se centra en los resultados de las regresiones cuantílicas.

Al observar los resultados para inmigrantes recientes y antiguos, encontramos mayor heterogeneidad y amplitud de las brechas que separan a los primeros de los nativos. Para los inmigrantes con mayor tiempo de asentamiento, en cambio, se aprecian distribuciones más suavizadas y, a excepción de los coeficientes asociados al percentil más alto de ingresos (percentil 90), los coeficientes estimados no son estadísticamente distintos de cero.

Al modelar el decil más bajo del logaritmo del ingreso encontramos que los inmigrantes recientes ganan un $27 \%$ menos que los nativos $^{5}$. Esta brecha se reduce a $10 \%$ en la mediana de los ingresos y se invierte a favor de los inmigrantes recientes en el decil más alto, en el que ganan 13,6\% más que los nativos (Tabla 3, Modelo 1). Entre los inmigrantes antiguos, la diferencia respecto al ingreso de los nativos sólo es significativa en el decil más alto, donde los inmigrantes antiguos ganan un 9,3\% más que los nativos.

Estos resultados muestran al menos dos escenarios muy contrastantes dentro de la población inmigrada. Por un lado, inmigrantes ocupados con bajos salarios que además son penalizados por su condición de inmigrantes y, por otro lado, inmigrantes ocupados con ingresos superiores a los de los nativos. Este último escenario sugiere que para un segmento de los inmigrantes las dificultades habituales de traducibilidad de experiencia laboral y credenciales educativas no afectarían sus ingresos y se insertarían en sectores altamente productivos. Un ejemplo de ello podría ser en las empresas transnacionales presentes en Uruguay que fomentan la movilidad temporal de trabajadores de alta y muy alta calificación (Arocena, Asconeguy, Mishra y Parodi, 2016). En estos sectores algunas habilidades no observables, como el manejo fluido de lenguas extranjeras y lenguajes de programación, podrían estar siendo reconocidas positivamente entre los inmigrantes recientes.

5 Como veremos más adelante esta diferencia en los ingresos, entre inmigrantes recientes y nativos en el percentil 10, es aún más pronunciada cuando se incluyen en el modelo la interacción entre condición migratoria y ascendencia étnico-racial (Modelo 2, en Tabla A3 en Anexo). 
TABLA 3

SELECCIÓN DE COEFICIENTES Y ERRORES ESTÁNDAR (EN PARÉNTESIS) DE LAS REGRESIONES CUANTÍLICAS SOBRE EL LOGARITMO DE LA REMUNERACIÓN POR HORA DE LA OCUPACIÓN PRINCIPAL. URUGUAY, 2013-2017

\begin{tabular}{|c|c|c|c|c|c|c|}
\hline & \multicolumn{3}{|c|}{ Modelo 1} & \multicolumn{3}{|c|}{ Modelo 2} \\
\hline & P10 & P50 & $P 90$ & P10 & P50 & P90 \\
\hline \multicolumn{7}{|l|}{$\begin{array}{l}\text { Condición migratoria } \\
\text { (ref. nativo) }\end{array}$} \\
\hline Inmigrante & $-0,274^{\star \star}$ & $-0,100^{\star \star \star}$ & $0,137^{\star \star \star}$ & $-0,394^{\star \star \star}$ & $-0,093^{\star \star \star}$ & $0,158^{\star \star}$ \\
\hline reciente & $(0,092)$ & $(0,018)$ & $(0,041)$ & $(0,110)$ & $(0,021)$ & $(0,053)$ \\
\hline Inmigrante & $-0,044$ & 0,012 & $0,093^{\star \star \star}$ & $-0,035$ & $0,0178^{\star}$ & $0,105^{\star \star \star}$ \\
\hline Antiguo & $(0,034)$ & $(0,010)$ & $(0,019)$ & $(0,029)$ & $(0,010)$ & $(0,020)$ \\
\hline \multicolumn{7}{|l|}{ Sexo (ref. varón) } \\
\hline Mujer & $-0,313^{\star \star \star}$ & $-0,167^{\star \star \star}$ & $-0,176^{\star \star \star}$ & $-0,313^{\star \star \star}$ & $-0,167^{\star \star \star}$ & $-0,176^{\star \star \star}$ \\
\hline & $(0,009)$ & $(0,002)$ & $(0,004)$ & $(0,009)$ & $(0,003)$ & $(0,004)$ \\
\hline \multicolumn{7}{|l|}{$\begin{array}{l}\text { Ascendencia étnico-racial } \\
\text { (ref. blanco) }\end{array}$} \\
\hline Afro & $-0,224^{\star \star \star}$ & $-0,0912^{\star \star \star}$ & $-0,056^{\star \star \star}$ & $-0,224^{\star \star \star}$ & $-0,091^{\star \star \star}$ & $-0,052^{\star \star \star}$ \\
\hline & $(0,023)$ & $(0,006)$ & $(0,011)$ & $(0,024)$ & $(0,006)$ & $(0,010)$ \\
\hline Otra & $-0,267^{\star \star \star}$ & $-0,067^{\star \star \star}$ & $-0,027^{\star}$ & $-0,269^{\star \star \star}$ & $-0,064^{\star \star \star}$ & $-0,020$ \\
\hline & $(0,037)$ & $(0,009)$ & $(0,015)$ & $(0,036)$ & $(0,011)$ & $(0,017)$ \\
\hline & & & & \multicolumn{3}{|c|}{$\begin{array}{c}\text { Interacciones condición migratoria y } \\
\text { ascendencia étnico racial }\end{array}$} \\
\hline Inmigrante reciente \# & & & & $0,424^{\star \star}$ & $-0,047$ & $-0,247^{\star \star}$ \\
\hline Afro & & & & $(0,211)$ & $(0,046)$ & $(0,119)$ \\
\hline Inmigrante reciente \# & & & & $0,739^{\star \star \star}$ & $-0,042$ & $-0,352^{\star}$ \\
\hline Otra & & & & $(0,186)$ & $(0,056)$ & $(0,187)$ \\
\hline Inmigrante antiguo \# & & & & $-0,234$ & $-0,1089^{\star}$ & $-0,067$ \\
\hline Afro & & & & $(0,245)$ & $(0,056)$ & $(0,090)$ \\
\hline Inmigrante antiguo \# & & & & $-0,171$ & $-0,053$ & $-0,191^{\star \star}$ \\
\hline Otra & & & & $(0,371)$ & $(0,048)$ & $(0,088)$ \\
\hline
\end{tabular}

${ }^{*} p<0,10,{ }^{* \star} p<0,05,{ }^{* * *} p<0,001$

Nota: «P» indica percentil. El modelo completo se presenta en la Tabla A3.

Fuente: elaboración propia con base en microdatos de la Encuesta Continua de Hogares del 2013 al 2017. 
La condición de mujer y la pertenencia a minorías étnicas, se asocia a una brecha de ingreso desfavorable para los tres percentiles. Estas brechas se van acortando conforme se avanza en los percentiles de ingreso, pero no desaparecen por completo. En cuanto a sus magnitudes, la desigualdad por sexo es la más pronunciada, alcanzando el $31 \%$ en el decil más bajo y $18 \%$ en el más alto (Tabla 3, Modelo 1). Igualmente, la desigualdad de ingresos por ascendencia étnico racial es muy pronunciada en el decil más bajo, donde la brecha que separa a la población afro y a otras minorías étnico-raciales de la población blanca es de $22,4 \%$ y $26,6 \%$, respectivamente. Para los percentiles medios y altos, esta diferencia pasa a ser de un dígito.

Hasta aquí se ha visto que la condición de inmigrante, ser mujer y la auto adscripción a minorías étnico-raciales inciden negativamente en la remuneración, pero, también interesa indagar qué ocurre cuando estas condiciones coinciden en un mismo individuo a partir de los resultados presentados en la Tabla $4^{6}$. El resultado encontrado se corresponde parcialmente con la hipótesis inicialmente planteada acerca de la agudización del efecto negativo de contar con múltiples condiciones de desigualdad, puesto que la acumulación de desventajas se observa en los percentiles bajos y medios del ingreso pero no en los altos.

En el primer decil, los inmigrantes recientes blancos tienen un ingreso 39\% menor que los nativos blancos (Tabla 4). En la mediana esta brecha se reduce a 9\%. Por el contrario, los inmigrantes recientes autoidentificados blancos que logran ocupar la posición del percentil 90, ganan un 15\% más que los nativos blancos. La diferencia en el ingreso por trabajo entre los inmigrantes antiguos y los nativos blancos es mucho menor en la parte baja y media de la distribución; mientras que la brecha positiva se mantiene en la parte superior donde los inmigrantes blancos antiguos ganan 10\% más que el grupo de referencia.

Quienes cumplen con la doble condición de ser inmigrantes recientes y afrodescendientes son fuertemente penalizados en sus ingresos especialmente en los percentiles medios y bajos. En el decil

$6 \mathrm{Al}$ establecer interacciones entre características categóricas, se establecen los grupos con todas las combinaciones posibles entre las dos variables dejando una combinación como referencia, en este caso el ser nativo y blanco. La suma de los coeficientes del modelo 2 (Tabla A3) se presenta en la Tabla 4, junto con los errores estándar y su significancia estadística. 
más bajo, este grupo percibe remuneraciones $85 \%$ menores a las de los nativos blancos. Esta brecha se reduce para los ingresos medios, aunque aún es importante y significativa (ganan 29\% menos). En cambio, en el decil más alto de ingresos esta diferencia no es significativa.

Por otro lado, el efecto conjunto de ser inmigrante antiguo y afrodescendiente reduce el ingreso en $49 \%$ respecto a ser nativo blanco en el primer decil. Esta diferencia disminuye a $18 \%$ en la mediana del ingreso hasta desaparecer en el decil más alto. Dentro de los deciles bajos y medios, la convergencia esperada de inmigrantes antiguos con nativos solo se verifica entre quienes se autoidentifican como blancos. En cambio, las remuneraciones de los inmigrantes afrodescendientes, continúan siendo un 50\% menor a la de los nativos blancos, incluso transcurridos 5 años desde su llegada al país.

Si consideramos la conjunción de la condición de inmigrante (antiguo o reciente) con otra ascendencia étnico racial minoritaria, constatamos que la brecha a favor de la población nativa blanca sólo es significativa en la mediana del ingreso y que quienes se autoidentifican como afrodescendientes perciben un ingreso menor al de quienes se identifican con otras minorías.

Por último, encontramos que en todos los grupos donde se combina la pertenencia a otras minorías étnico-raciales (indígenas y otros grupos) con la condición de inmigrante se reduce la brecha respecto al grupo de referencia (nativo blanco) conforme transcurre el tiempo desde la llegada a Uruguay. Esta doble desigualdad se corrobora en los percentiles 10 y 50 pero su efecto desaparece en el percentil 90.

La condición migratoria y la pertenencia a minorías étnico-raciales se traduce en la percepción de menores ingresos, pero únicamente para quienes se ubican en los percentiles bajos y medios. Para los percentiles más altos, este efecto conjunto desaparece, pero tampoco se conserva el efecto positivo que se aprecia en este percentil cuando se atiende únicamente a la condición de inmigrante reciente. Entonces, los resultados no nos permiten descartar que el efecto conjunto de estas dos condiciones sea un problema en este nivel de ingreso. 
TABLA 4

ESTIMACIONES PARA LAS COMBINACIONES LINEALES DE LOS COEFICIENTES DE CONDICIÓN MIGRATORIA, ASCENDENCIA ÉTNICO RACIAL E INTERACCIÓN DE AMBAS VARIABLES. URUGUAY, 2013-2017

\begin{tabular}{|c|c|c|c|c|c|c|c|}
\hline \multirow{3}{*}{$\begin{array}{l}\text { Condición } \\
\text { migratoria } \\
\text { (Ref. Nativo) }\end{array}$} & \multirow{3}{*}{$\begin{array}{l}\text { Ascendencia } \\
\text { étnico racial } \\
\text { (Ref. Blanco) }\end{array}$} & \multicolumn{2}{|c|}{ [P10] } & \multicolumn{2}{|c|}{ [P50] } & \multicolumn{2}{|c|}{ [P90] } \\
\hline & & Coef. & E.E. & Coef. & E.E. & Coef. & E.E. \\
\hline & & & & & & & \\
\hline In. reciente & Blanco & $-0,394^{\star \star \star}$ & 0,110 & $-0,093^{\star \star \star}$ & 0,021 & $0,158^{\star \star}$ & 0,053 \\
\hline In. antiguo & Blanco & $-0,036$ & 0,029 & $-0,017^{\star}$ & 0,010 & $0,105^{\star \star \star}$ & 0,020 \\
\hline Nativo & Afro & $-0,224^{\star \star \star}$ & 0,024 & $-0,091^{\star \star \star}$ & 0,006 & $-0,052^{\star \star \star}$ & 0,010 \\
\hline Nativo & Otro & $-0,269^{\star \star \star}$ & 0,036 & $-0,064^{\star \star \star}$ & 0,011 & $-0,020$ & 0,017 \\
\hline In. reciente & Afro & $-0,852^{\star \star \star}$ & 0,260 & $-0,292^{\star \star \star}$ & 0,068 & -0.039 & 0,109 \\
\hline In. reciente & Otro & 0,076 & 0,161 & $-0,199$ ** & 0,067 & $-0,214$ & 0,153 \\
\hline In. antiguo & Afro & $-0,494^{\star *}$ & 0,242 & $-0,182$ ** & 0,062 & 0,014 & 0,101 \\
\hline In. antiguo & Otro & $-0,475$ & 0,306 & $-0,099^{\star \star}$ & 0.046 & $-0,106$ & 0,076 \\
\hline
\end{tabular}

Nota: «P» indica percentil; «EE» error estándar.

Fuente: elaboración propia con base en estimaciones de los modelos 1 y 2 presentados en la Tabla A3, en Anexo.

\section{CONCLUSIONES}

La evidencia que surge del análisis aquí realizado indica que la inmigración reciente es más educada que la población nativa o la inmigración histórica de origen europeo y fronterizo. A su vez, debido fundamentalmente a la población de origen caribeño (Venezuela, Cuba y República Dominicana) y andino (Perú), su composición étnico racial difiere de la de flujos intrarregionales históricos procedentes mayormente de Brasil y Argentina. Estos rasgos, sumados a las condiciones de segmentación por género, ocupación y ascendencia étnico-racial presentes en Uruguay, auguran una acumulación de desigualdades que perjudicaría a los inmigrantes recientes, particularmente a las mujeres afrodescendientes. Sin embargo, nuestros resultados matizan esta hipótesis.

Por una parte, las estimaciones multivariadas confirman la existencia de una brecha desfavorable a la inmigración reciente que se reduce - sin desaparecer- a medida que transcurre el tiempo desde la llegada a Uruguay. No obstante, este resultado es parcialmente 
cierto cuando se consideran los distintos niveles de ingreso. Las brechas que perjudican a los inmigrantes únicamente persisten entre aquellos que se insertan en ocupaciones con ingresos bajos y medios. Ello coincide con la perspectiva de los mercados duales según la cual la segmentación entre un sector primario y secundario se mantiene, incluso más allá del tiempo de asentamiento.

La condición de mujer y la pertenencia a minorías étnico raciales, se asocia a una brecha desfavorable para los tres percentiles de ingreso. Estas brechas muestran un efecto persistente a lo largo de la distribución que se va acortando conforme avanzamos en ella, sin desaparecer por completo. Conviene recordar que dentro de ambas desigualdades, la de género es la más pronunciada en los tres percentiles y la asociada a la ascendencia étnico racial es muy pronunciada en el decil más bajo.

En cuanto a nuestra hipótesis sobre la existencia de entrelazamientos entre los distintos ejes de segmentación del mercado laboral, encontramos que la condición étnico-racial se superpone a la de inmigrante afectando a quienes dentro de este grupo se autoidentifican como afrodescendientes. Esta doble penalización sólo se verifica en los niveles de ingresos más bajos y medios, en cambio, se reduce entre quienes llevan más tiempo en Uruguay y desaparece en los estratos más altos de la distribución de ingresos.

Estaríamos entonces frente a la coexistencia de dobles desventajas (condición migratoria y ascendencia étnico racial) que se superponen a una tercera dada por los distintos grupos de ingresos; así como frente a triples desventajas dentro de la población nativa donde persiste la penalización sobre la remuneración de las mujeres pertenecientes a minorías étnico-raciales y ocupadas en sectores de baja productividad (género, ascendencia étnico racial y clase ocupacional).

Entendemos que la evidencia recogida reafirma la importancia de considerar que la segmentación del mercado laboral no es dual en este caso, sino que se produce en múltiples estratos definidos según complejas interseccionalidades. El caso uruguayo difiere parcialmente de lo que ocurre en el norte global cuando se consideran los estratos más altos de la distribución de ingreso, y se asemeja a lo observado en Brasil, donde las diferencias entre inmigrantes recientes y nativos son favorables a los primeros (Sala y Rios Neto, 2006). Entonces, la evidencia para Uruguay junto a la de Brasil y Chile -donde recordemos, no se corroboran brechas en el ingreso entre inmigrantes y nativos- llama a revisar el alcance interpretativo de 
la perspectiva de los mercados duales para comprender la incorporación al mercado de trabajo, al menos en contextos de migración sur-sur como el uruguayo.

Asimismo, estos resultados muestran una vez más las limitaciones de adoptar la perspectiva asimilacionista para comprender este caso de migración sur-sur en dos sentidos. Por una parte, desde el asimilacionismo podría entenderse que las similitudes entre nativos e inmigrantes en cuanto a los niveles de cobertura de la seguridad social, muestran un panorama alentador sobre la base de la convergencia entre ambos grupos. Pero lo que esta perspectiva oculta es la persistencia de problemas de calidad del empleo o de remuneraicón para el conjunto de los trabajadores de ambos grupos. Por otra parte, el tiempo transcurrido tras la inmigración parece contribuir positivamente hacia la convergencia de ingresos con la población nativa pero únicamente para los trabajadores de ingresos medios y bajos. Este proceso es acorde a lo esperado por la perspectiva de la asimilación segmentada (Aysa-Lastra y Cachón, 2013; Portes, Fernández-Kelly y Haller, 2006), en tanto la asimilación se produce en un solo segmento. Mientras tanto en los niveles altos de ingreso no se corrobora un proceso de asimilación; los inmigrantes tienen, con independencia del tiempo transcurrido en el país, mayor ingreso que los nativos.

En términos metodológicos, es importante resaltar que la heterogeneidad presente en la inmigración reciente y las desigualdades de la distribución de ingresos por trabajo - corroborables incluso entre los trabajadores nativos-, dejan en evidencia la importancia de considerar modelos que no estimen únicamente en la media de la distribución. Como ya anotamos, esto es especialmente relevante para visibilizar la coexistencia de inserciones laborales heterogéneas - que no se agotan en la perspectiva de la dualidad - en contextos de acogida donde no es despreciable la incidencia del empleo desprotegido.

Estos resultados deben considerarse a la luz de las limitaciones propias de las fuentes de información disponibles para el caso de estudio. Primero, los datos de la ECH aquí utilizados parten de una muestra que excluye a aquellos inmigrantes que residen en viviendas colectivas y que son quienes logran una peor inserción laboral. Segundo, comprender en qué medida las desigualdades identificadas se traducen en la inclusión laboral y social de los inmigrantes recientes requeriría de datos longitudinales e información específica sobre el estatus documental de los inmigrantes, ambas no disponibles en Uruguay por el momento. 


\section{REFERENCIAS}

Adsera, A., y Chiswick, B. R. (2007). Are there gender and country of origin differences in immigrant labor market outcomes across European destinations? Journal of Population Economics, 20(3), 495.

Amarante, V., y Espino, A. (2004). La segregación ocupacional de género y las diferencias en las remuneraciones de los asalariados privados. Uruguay, 1990-2000. Desarrollo Económico, 44(173), 109-129.

Anderson, K. (2015). Can immigrants ever earn as much as native workers? IZA World of Labor, June, 1-10.

Arceo Gómez, E., y Campos Vázquez, R. (2014). Discriminación en el mercado laboral mexicano: un experimento de campo. En G. Meixueiro Nájera y S. Moreno Pérez (Ed.) Premio Nacional de Investigación y Opinión Pública 2012 (pp. 123-157). Ciudad de México: CESOP.

Arocena, F., Asconeguy, M., Mishra, A., y Parodi, R. (2016). Estudio sociocultural de los nuevos inmigrantes indios en Uruguay: los chinos no vienen y los indios llegan y se van. ¿Por qué?. Cuadernos Del Claeh, 35(103), 63-79.

Aysa-Lastra, M., y Cachón, L. (2013). Segmented Occupational Mobility: The Case of Non-EU Immigrants in Spain. Revista Española de Investigaciones Sociológicas, 144, 23-47.

Bernardi, F., Garrido, L., y Miyar, M. (2011). The Recent Fast Upsurge of Immigrants in Spain and Their Employment Patterns and Occupational Attainment. International Migration, 49(1), 148-187.

Borraz, F., y Robano, C. (2010). Brecha salarial en Uruguay. Revista de Análisis Económico, 25(1), 49-77.

Bucheli, M., y Cabella, W. (2007). El perfil demográfico y socioeconómico de la población uruguaya según su ascendencia racial. Montevideo: INE, PNUD, UNFPA.

Bucheli, M., y Sanromán, G. (2005). Salarios femeninos en el Uruguay: ¿Existe un techo de cristal? Revista de Economía, 12(2), 63-88.

Bucheli, M., y Sanromán, G. (2010). Descomposición de las brechas salariales entre blancos y afrodescendientes a lo largo de la distribución de salarios, Serie Documento de Trabajo, DT 14/10, Departamento de Economía, Facultad de Ciencias Sociales, Universidad de la República, Uruguay. Recuperado de: http://cienciassociales.edu.uy/departamentodeeconomia/wpcontent/uploads/sites/2/2015/12/1410_esp.pdf [31/05/2019]

Bucheli, M., y Porzecanski, R. (2008). Desigualdad salarial y discriminación por raza en el mercado de trabajo uruguayo. En L. Scuro (Ed.), Población afrodescendiente y desigualdades étnico-raciales en Uruguay (pp. 127-143). Montevideo: PNUD.

Cabella, W., Nathan, M., y Tenenbaum, M. (2013). La población afro uruguaya en el censo 2011. Montevideo: INE, UNFPA.

Caicedo, M. (2015). La desigualdad salarial entre inmigrantes latinoamericanos y nativos en Estados Unidos (1980-2010). Norteamérica, 10, 1, 136-164. 
Cerrutti, M., y Maguid, A. (2006). Inserción laboral e ingresos de migrantes limítrofes y del Perú en el Área Metropolitana de Buenos Aires, 2005. Reunión de Expertos sobre Población y Pobreza en América Latina y el Caribe. Santiago de Chile: CEPAL.

Espino, A. (2013). Brechas salariales en Uruguay: género, segregación y desajustes por calificación. Problemas del Desarrollo, 174(44), 89-117.

Fellini, I., y Guetto, R. (2019). A “U-Shaped” Pattern of Immigrants' Occupational Careers? A Comparative Analysis of Italy, Spain, and France. International Migration Review, 53(1), 26-58.

Gandini, L., y Lozano-Ascencio, F. (2015). The Effects of the Crisis on Occupational Segregation of Skilled Migrants from Latin America and the Caribbean in the United States, 2006-2012. Population, Space and Place, 22(5), 441-456.

ILO. (2019). ILOSTAT. ILO. Recuperado de: https://ilostat.ilo.org/ [31/05/2019]

INE. (2015). Subempleo 2015. Montevideo: INE. Recuperado de: http://www. ine.gub.uy/c/document_library/get_file?uuid=e5725619-6c21-415c-97f63d98280b6183\&groupId=10181 [31/05/2019]

INE (2019). Cotizaciones al público - Principales monedas. Montevideo: INE. Recuperado de: http://www.ine.gub.uy/c/document_library/get_ file?uuid=1dcbe20a-153b-4caf-84a7-7a030d109471 [31/05/2019]

Kaas, L., y Manger, C. (2010), Ethnic Discrimination in Germany's Labour Market: A Field Experiment, No 4741, IZA Discussion Papers, Institute of Labor Economics (IZA).

Koolhaas, M, Prieto, V. y Robaina, S. (2017). Los uruguayos ante la inmigración. Encuesta Nacional de actitudes de la población nativa hacia inmigrantes extranjeros y retornados, No 1/2017, Serie Documentos de Trabajo del Programa de Población. Recuperado de: https:/www.colibri.udelar. edu.uy/jspui/handle/20.500.12008/19985 [13/03/2019]

Lubotsky, D. (2007). Chutes or Ladders? A Longitudinal Analysis of Immigrant Earnings', Journal of Political Economy. Journal of Political Economy, 115(5), 820-867.

Martínez, J., y Orrego, C. (2016). Nuevas tendencias y dinámicas migratorias en América Latina y el Caribe. Santiago de Chile: CEPAL

Méndez, L. (2018) “Immigrants' over-education and wage penalty. Evidence from Uruguay”. Serie Documentos de Trabajo, DT 16/2018. Instituto de Economía, Facultad de Ciencias Económicas y Administración, Universidad de la República, Uruguay

MIDES (2017). Caracterización de las nuevas corrientes migratorias en Uruguay Nuevos orígenes latinoamericanos: estudio de caso de las personas peruanas y dominicanas Informe final. Montevideo: MIDES.

Mora Salas. M. (2010). Ajuste y empleo: La precarización del trabajo asalariado en la era de la globalización. México, D.F: El Colegio de México, Centro de Estudios Sociológicos. 
Muñoz Comet, J. (2013). ¿Qué trabajos ocupan quienes abandonan el desempleo? Diferencias entre españoles y extranjeros en un contexto de cambio económico. Revista Internacional de Sociología, 72(2), 353-376.

OEA-SICREMI (2017). International migration in the Americas. Fourth Report of the Continuous Reporting System on International Migration in the Americas (SICREMI). Washington D.C.: OAS.

Pérez Sáinz, J. P., y Mora Salas, M. (2008). Excedente económico y persistencia de las desigualdades en América Latina. Una propuesta analítica y metodológica. España: Fundación Carolina

Petitpas Brahm, M. L. (2017). Integración económica de los inmigrantes en Chile (Tesis inédita de magíster). Pontificia Universidad Católica de Chile, Santiago.

Prieto, V., Robaina, S., y Koolhaas, M. (2016). Acceso y calidad del empleo de la inmigración reciente en Uruguay. REMHU: Revista Interdisciplinar da Mobilidade Humana, 24(48), 121-144.

Portes, A., Fernández-Kelly, P., y Haller, W. (2006). La asimilación segmentada sobre el terreno: la nueva segunda generación al inicio de la vida adulta. Migraciones, 19, 7-58.

Rivas, F., y Rossi, M. (2000). Discriminación salarial en el Uruguay 19911997. Documentos de trabajo 7, Departamento de Economía, Facultad de Ciencias Sociales, Universidad de la República, 0-22.

Rodríguez-Planas, N., y Nollenberger, N. (2016). Labor market integration of new immigrants in Spain. IZA Journal of Labor Policy, 5(1), 4.

Sala, G. A., y Rios Neto, E. (2006). Diferencias salariales entre trabajadores migrantes del Cono Sur de América Latina y trabajadores brasileños. En N. C. Meichtry, A. Pellegrino y E. L. Bologna (Ed.), Migrantes Latinoamericanos: El estado de las investigaciones en la región (pp. 119-148). Córdoba: ALAP-UNFPA.

Scuro Somma, L. (2008). Pablación afrodescendientes y desigualdades étnicoraciales en Uruguay. Montevideo: PNUD.

Torres, E., y Celton, D. (2009). Discriminación salarial en Argentina entre nativos y paraguayos. Cuadernos Geográficos de la Universidad de Grana$d a, 45(2), 263-285$.

Valles, M., Cea D’Ancona, M., y Domínguez, G. (2017). Discriminación múltiple e inmigración: huellas de discurso institucional, académico y de la población. Revista Española De Investigaciones Sociológicas (REIS), 159, 135-150.

Villarreal, A., y Tamborini, C. (2018). Immigrants' Economic Assimilation: Evidence from Longitudinal Earnings Records. American Sociological Review, 83(4), 686-715. 


\section{ANEXOS}

TABLA A1

COEFICIENTES Y ERRORES ESTÁNDAR (EN PARÉNTESIS)

DEL MODELO LOGÍSTICO PARA LA PROBABILIDAD DE ESTAR OCUPADO DE LA POBLACIÓN EN EDAD DE TRABAJAR. URUGUAY, 2013-2017

\begin{tabular}{cc}
\hline Odds ratio+ \\
(error estándar)
\end{tabular}

Condición migratoria (ref. nativo)

$\begin{array}{cc}\text { Inmigrante reciente } & 0,437^{\star \star \star} \\ & (0,025) \\ \text { Inmigrante antiguo } & 0,968 \\ & (0,028)\end{array}$

Sexo (ref. hombre)

$0,359^{\star \star \star}$
$(0,003)$

Ascendencia étnico-racial (ref. blanca)

$\begin{array}{cc}\text { Afro } & 1,024 \\ & (0,019) \\ \text { Otra } & 1,062^{\star *} \\ & (0,031) \\ & 1,338^{\star \star \star} \\ & (0,002) \\ & 0,996^{\star \star \star} \\ & (0,000) \\ & 1,129^{\star \star \star} \\ & (0,001)\end{array}$

Asistencia escolar (ref. no asiste)

$0,293^{\star \star \star}$
Asiste
$(0,004)$

Residencia (ref. urbana)

\begin{tabular}{|c|c|}
\hline & $1,134^{\star \star \star}$ \\
\hline
\end{tabular}




\begin{tabular}{|c|c|c|}
\hline & & $\begin{array}{c}\text { Odds ratio+ } \\
\text { (error estándar) }\end{array}$ \\
\hline \multicolumn{3}{|l|}{ Posición en el hogar (ref. jefe/a) } \\
\hline & Esposo/a & $0,543^{\star \star \star}$ \\
\hline & & $(0,006)$ \\
\hline & Hijo/a & $0,383^{\star \star \star}$ \\
\hline & & $(0,005)$ \\
\hline & Otro/a & $0,486^{\star \star \star}$ \\
\hline & & $(0,008)$ \\
\hline \multicolumn{3}{|l|}{ Situación conyugal (ref. no unido/a) } \\
\hline & Unido/a & $0,967^{\star \star}$ \\
\hline & & $(0,011)$ \\
\hline \multirow[t]{2}{*}{ Tasa de dependencia intra-familiar } & & $0,832^{\star \star \star}$ \\
\hline & & $(0,005)$ \\
\hline \multicolumn{3}{|l|}{ Año de la encuesta (ref. 2013) } \\
\hline \multirow[t]{2}{*}{2014} & & 1,007 \\
\hline & & $(0,012)$ \\
\hline \multirow[t]{2}{*}{2015} & & $0,948^{\star \star \star}$ \\
\hline & & $(0,011)$ \\
\hline \multirow[t]{2}{*}{2016} & & $0,915^{\star \star \star}$ \\
\hline & & $(0,011)$ \\
\hline \multirow[t]{2}{*}{2017} & & $0,872^{\star \star \star}$ \\
\hline & & $(0,010)$ \\
\hline Observaciones & & 503.066 \\
\hline $\mathrm{R}^{2} \mathrm{Mc}$ Fadden & & 0,361 \\
\hline $\mathrm{R}^{2} \mathrm{Mc}$ Fadden Ajustado & & 0361 \\
\hline Devianza & & 438341,5 \\
\hline Verosimilitud & & $-219170,7$ \\
\hline
\end{tabular}

${ }^{*} p<0,10,{ }^{* *} p<0,05,{ }^{* * *} p<0,001$

Fuente: elaboración propia con base en microdatos de la Encuesta Continua de Hogares del 2013 al 2017. 
TABLA A2

COEFICIENTES Y ERRORES ESTÁNDAR (EN PARÉNTESIS) DE REGRESIONES POR MÍNIMOS CUADRADOS ORDINARIOS SOBRE EL LOGARITMO DE LA REMUNERACIÓN POR HORA DE LA OCUPACIÓN PRINCIPAL. URUGUAY, 2013-2017

\begin{tabular}{|c|c|c|c|c|}
\hline & & MCO 1 & MCO 2 & MCO 3 \\
\hline \multicolumn{5}{|c|}{ Condición migratoria (ref, nativo) } \\
\hline & Inm, reciente & $-0,111^{\star \star \star}$ & $-0,089^{\star \star}$ & $-0,139^{\star \star \star}$ \\
\hline & & $(0,032)$ & $(0,034)$ & $(0,029)$ \\
\hline & Inm,antiguo & $-0,011$ & $-0,001$ & 0,000 \\
\hline & & $(0,016)$ & $(0,019)$ & $(0,014)$ \\
\hline \multicolumn{5}{|l|}{ Sexo (ref, varón) } \\
\hline & Mujer & $-0,2412^{\star \star \star}$ & $-0,241^{\star \star \star}$ & $-0,242^{\star \star \star}$ \\
\hline & & $(0,004)$ & $(0,004)$ & $(0,004)$ \\
\hline \multicolumn{5}{|c|}{ Ascendencia étnico-racial (ref, blanca) } \\
\hline & Afro & $-0,119^{\star \star \star}$ & $-0,119^{\star \star \star}$ & $-0,118^{\star \star \star}$ \\
\hline & & $(0,010)$ & $(0,009)$ & $(0,009)$ \\
\hline & Otra & $-0,1201^{\star \star \star}$ & $-0,121^{\star \star \star}$ & $-0,118^{\star \star \star}$ \\
\hline & & $(0,015)$ & $(0,013)$ & $(0,014)$ \\
\hline \multirow[t]{2}{*}{ Edad } & & $0,054^{\star \star \star}$ & $0,054^{\star \star \star}$ & $0,054^{\star \star \star}$ \\
\hline & & $(0,001)$ & $(0,001)$ & $(0,001)$ \\
\hline \multirow[t]{2}{*}{ Edad2 } & & $-0,001^{\star \star \star}$ & $-0,001^{\star \star \star}$ & $-0,001^{\star \star \star}$ \\
\hline & & $(0,000)$ & $(0,000)$ & $(0,000)$ \\
\hline \multirow[t]{2}{*}{ Años de estudio } & & $0,066^{\star \star \star}$ & $0,066^{\star \star \star}$ & $0,066^{\star \star \star}$ \\
\hline & & $(0,002)$ & $(0,002)$ & $(0,002)$ \\
\hline \multirow[t]{2}{*}{ Años de estudio2 } & & $0,000^{\star *}$ & $0,000^{\star}$ & $0,000^{\star \star}$ \\
\hline & & $(0,000)$ & $(0,000)$ & $(0,000)$ \\
\hline \multicolumn{5}{|l|}{ Residencia (ref. urbana) } \\
\hline & Rural & $-0,086^{\star \star \star}$ & $-0,086^{\star \star \star}$ & $-0,086^{\star \star \star}$ \\
\hline & & $(0,006)$ & $(0,005)$ & $(0,005)$ \\
\hline \multicolumn{5}{|c|}{ Posición en el hogar (ref. jefe/a) } \\
\hline & Cónyuge & $-0,132^{\star \star \star}$ & $-0,132^{\star \star \star}$ & $-0,132^{\star \star \star}$ \\
\hline & & $(0,005)$ & $(0,005)$ & $(0,005)$ \\
\hline & Niño/a & $-0,204^{\star \star \star}$ & $-0,200^{\star \star \star}$ & $-0,200^{\star \star \star}$ \\
\hline & & $(0,006)$ & $(0,007)$ & $(0,007)$ \\
\hline & Otro/a & $-0.1666^{\star \star \star}$ & $-0.1666^{\star \star \star}$ & $-0.1668^{\star \star \star}$ \\
\hline & & $(0.010)$ & $(0.009)$ & $(0.009)$ \\
\hline \multicolumn{5}{|c|}{ Situación conyugal (ref, no unido/a) } \\
\hline & Unido/a & $0,060^{\star \star \star}$ & $0,060^{\star \star \star}$ & $0,060^{\star \star \star}$ \\
\hline & & $(0,005)$ & $(0,005)$ & $(0,005)$ \\
\hline Tasa de dependencia & & $-0,011^{\star \star}$ & $-0,011^{\star \star \star}$ & $-0,011^{\star \star \star}$ \\
\hline intra-familiar & & $(0,004)$ & $(0,003)$ & $(0,003)$ \\
\hline
\end{tabular}




\begin{tabular}{|c|c|c|c|}
\hline & MCO 1 & MCO 2 & MCO 3 \\
\hline \multicolumn{4}{|l|}{$\begin{array}{l}\text { Clase ocupacional (ref. No manual } \\
\text { de alta calificación) }\end{array}$} \\
\hline No manual baja calificación, & $\begin{array}{c}-0,313^{\star \star \star} \\
(0,006)\end{array}$ & $\begin{array}{c}-0,313^{\star \star \star} \\
(0,006)\end{array}$ & $\begin{array}{c}-0,313^{\star \star \star} \\
(0,006)\end{array}$ \\
\hline Manual calificada & $\begin{array}{c}-0,295^{\star \star \star} \\
(0,007)\end{array}$ & $\begin{array}{c}-0,295^{\star \star \star} \\
(0,007)\end{array}$ & $\begin{array}{c}-0,295^{\star \star \star} \\
(0,007)\end{array}$ \\
\hline Manual no calificado & $\begin{array}{c}-0,377^{\star * *} \\
(0,008)\end{array}$ & $\begin{array}{c}-0,377^{\star \star \star} \\
(0,007)\end{array}$ & $\begin{array}{c}-0,377^{\star \star \star} \\
(0,007)\end{array}$ \\
\hline \multicolumn{4}{|l|}{ Cantidad de trabajos (ref, uno) } \\
\hline dos y más & $\begin{array}{c}0,141^{\star \star \star} \\
(0,005)\end{array}$ & $\begin{array}{c}0,141^{\star \star *} \\
(0,006)\end{array}$ & $\begin{array}{c}0,141^{\star \star *} \\
(0,006)\end{array}$ \\
\hline \multicolumn{4}{|l|}{ Sector (ref, privado) } \\
\hline Sector público & $\begin{array}{c}0,303^{\star \star \star} \\
(0,004)\end{array}$ & $\begin{array}{c}0,303^{\star \star \star} \\
(0,005)\end{array}$ & $\begin{array}{c}0,303^{\star \star \star} \\
(0,005)\end{array}$ \\
\hline \multicolumn{4}{|l|}{ Año de la encuesta (ref, 2013) } \\
\hline 2014 & $\begin{array}{c}0,0501^{\star \star \star} \\
(0,006)\end{array}$ & $\begin{array}{c}0,051^{\star \star \star} \\
(0,006)\end{array}$ & $\begin{array}{c}0,051^{\star \star \star} \\
(0,006)\end{array}$ \\
\hline 2015 & $\begin{array}{c}0,052^{\star \star \star} \\
(0,006)\end{array}$ & $\begin{array}{c}0,052^{\star \star \star} \\
(0,006)\end{array}$ & $\begin{array}{c}0,052^{\star \star \star} \\
(0.006)\end{array}$ \\
\hline 2016 & $\begin{array}{c}0,056^{\star \star *} \\
(0,006)\end{array}$ & $\begin{array}{c}0,056^{\star \star *} \\
(0.006)\end{array}$ & $\begin{array}{c}0,056^{\star \star \star} \\
(0,006)\end{array}$ \\
\hline 2017 & $\begin{array}{c}0,108^{\star \star \star} \\
(0,006)\end{array}$ & $\begin{array}{c}0.1078^{\star \star \star} \\
(0,006)\end{array}$ & $\begin{array}{c}0,108^{\star \star \star} \\
(0,006)\end{array}$ \\
\hline Inm.reciente \# Mujer & & $\begin{array}{l}-0,051 \\
(0,053)\end{array}$ & \\
\hline Inm.antiguo \# Mujer & & $\begin{array}{l}-0,022 \\
(0,027)\end{array}$ & \\
\hline Inm.reciente \# Afro & & & $\begin{array}{l}0,153^{*} \\
(0,090)\end{array}$ \\
\hline Inm.reciente \# Otra & & & $\begin{array}{l}0,191^{*} \\
(0,100)\end{array}$ \\
\hline Inm.antiguo \# Afro & & & $\begin{array}{l}-0,132^{*} \\
(0,070)\end{array}$ \\
\hline Inm.antiguo \# Otra & & & $\begin{array}{c}-0,133^{\star \star} \\
(0,064)\end{array}$ \\
\hline Constante & $\begin{array}{c}3,216^{\star \star \star} \\
(0,027)\end{array}$ & $\begin{array}{c}3.215^{\star \star *} \\
(0,023)\end{array}$ & $\begin{array}{c}3,215^{\star \star \star} \\
(0,023)\end{array}$ \\
\hline $\mathrm{R}^{2}$ & 0,217 & 0,217 & 0,217 \\
\hline Observaciones & 289.817 & 289.817 & 289.817 \\
\hline
\end{tabular}

${ }^{*} p<0.10,{ }^{* *} p<0.05,{ }^{* * \star} p<0.001$

Fuente: elaboración propia con base en microdatos de la Encuesta Continua de Hogares del 2013 al 2017. 
TABLA A3

COEFICIENTES Y ERRORES ESTÁNDAR (EN PARÉNTESIS)

DE LAS REGRESIONES CUANTÍLICAS SOBRE EL LOGARITMO DE LA REMUNERACIÓN POR HORA DE LA OCUPACIÓN PRINCIPAL. URUGUAY, 2013-2017

\begin{tabular}{|c|c|c|c|c|c|c|}
\hline & \multicolumn{3}{|c|}{ Modelo1 } & \multicolumn{3}{|c|}{ Model02 } \\
\hline & Q10 & Q50 & Q90 & Q10 & Q50 & Q90 \\
\hline \multicolumn{7}{|l|}{$\begin{array}{l}\text { Condición migratoria } \\
\text { (ref. nativo) }\end{array}$} \\
\hline Inm.reciente & $\begin{array}{c}-0,274^{\star \star} \\
(0,092)\end{array}$ & $\begin{array}{c}-0,100^{\star \star \star} \\
(0,018)\end{array}$ & $\begin{array}{c}0,137^{\star \star \star} \\
(0,041)\end{array}$ & $\begin{array}{c}-0,394^{\star \star \star} \\
(0,110)\end{array}$ & $\begin{array}{c}-0,093^{\star \star \star} \\
(0,021)\end{array}$ & $\begin{array}{l}0,158^{\star *} \\
(0,053)\end{array}$ \\
\hline Inm.antiguo & $\begin{array}{l}-0,044 \\
(0,034)\end{array}$ & $\begin{array}{c}0,012 \\
(0,010)\end{array}$ & $\begin{array}{c}0,093^{\star \star \star} \\
(0,019)\end{array}$ & $\begin{array}{l}-0,036 \\
(0,029)\end{array}$ & $\begin{array}{l}0,018^{\star} \\
(0,010)\end{array}$ & $\begin{array}{c}0,105^{\star \star \star} \\
(0,020)\end{array}$ \\
\hline \multicolumn{7}{|l|}{ Sexo (ref. varón) } \\
\hline Mujer & $\begin{array}{c}-0,313^{\star \star \star} \\
(0,009)\end{array}$ & $\begin{array}{c}-0,167^{\star \star \star} \\
(0,002)\end{array}$ & $\begin{array}{c}-0,176^{\star \star \star} \\
(0,004)\end{array}$ & $\begin{array}{c}-0,313^{\star \star \star} \\
(0,009)\end{array}$ & $\begin{array}{c}-0,167^{\star \star \star} \\
(0,003)\end{array}$ & $\begin{array}{c}-0,176^{\star * *} \\
(0,004)\end{array}$ \\
\hline \multicolumn{7}{|l|}{$\begin{array}{l}\text { Ascendencia étnico-racial } \\
\text { (ref. blanco) }\end{array}$} \\
\hline Afro & $\begin{array}{c}-0,224^{\star \star *} \\
(0,023)\end{array}$ & $\begin{array}{c}-0,092^{\star * *} \\
(0,006)\end{array}$ & $\begin{array}{c}-0,056^{\star \star *} \\
(0,011)\end{array}$ & $\begin{array}{c}-0,224^{\star \star \star} \\
(0,024)\end{array}$ & $\begin{array}{c}-0,091^{\star * *} \\
(0,006)\end{array}$ & $\begin{array}{c}-0,052^{\star \star *} \\
(0,010)\end{array}$ \\
\hline Otra & $\begin{array}{c}-0,267^{\star \star \star} \\
(0,037)\end{array}$ & $\begin{array}{c}-0,067^{\star \star \star} \\
(0,009)\end{array}$ & $\begin{array}{l}-0,027^{\star} \\
(0,015)\end{array}$ & $\begin{array}{c}-0,270^{\star \star \star} \\
(0,036)\end{array}$ & $\begin{array}{c}-0,064^{\star \star \star} \\
(0,011)\end{array}$ & $\begin{array}{l}-0,020 \\
(0,017)\end{array}$ \\
\hline Edad & $\begin{array}{c}0,109^{\star \star *} \\
(0,003)\end{array}$ & $\begin{array}{c}0,036^{\star \star \star} \\
(0,001)\end{array}$ & $\begin{array}{l}0,022^{\star \star \star} \\
(0,001)\end{array}$ & $\begin{array}{l}0,109^{\star \star \star} \\
(0,004)\end{array}$ & $\begin{array}{c}0,036^{\star \star \star} \\
(0,001)\end{array}$ & $\begin{array}{c}0,021^{\star \star *} \\
(0,001)\end{array}$ \\
\hline $\mathrm{Edad}^{2}$ & $\begin{array}{c}-0,001^{\star \star \star} \\
(0,000)\end{array}$ & $\begin{array}{c}-0,000^{\star \star \star} \\
(0,000)\end{array}$ & $\begin{array}{l}-0,000^{\star \star \star} \\
(0.000)\end{array}$ & $\begin{array}{c}-0,001^{\star \star \star \star} \\
(0,000)\end{array}$ & $\begin{array}{c}-0,000^{\star \star \star} \\
(0,000)\end{array}$ & $\begin{array}{c}-0,000^{\star \star \star} \\
(0.000)\end{array}$ \\
\hline Años de educación & $\begin{array}{c}0,139^{\star \star \star} \\
(0,005)\end{array}$ & $\begin{array}{c}0,046^{\star \star \star} \\
(0,002)\end{array}$ & $\begin{array}{c}0,032^{\star \star \star} \\
(0,002)\end{array}$ & $\begin{array}{c}0,139^{\star \star \star} \\
(0,005)\end{array}$ & $\begin{array}{c}0,046^{\star \star \star} \\
(0,002)\end{array}$ & $\begin{array}{c}0,032^{\star \star \star} \\
(0,002)\end{array}$ \\
\hline Años de educación2 & $\begin{array}{c}-0,002^{\star \star \star} \\
(0,000)\end{array}$ & $\begin{array}{c}0,001^{\star \star \star} \\
(0,000)\end{array}$ & $\begin{array}{c}0,002^{\star \star \star} \\
(0,000)\end{array}$ & $\begin{array}{c}-0,002^{\star \star \star} \\
(0,000)\end{array}$ & $\begin{array}{c}0,001^{\star \star \star} \\
(0,000)\end{array}$ & $\begin{array}{c}0,002^{\star \star \star} \\
(0,000)\end{array}$ \\
\hline \multicolumn{7}{|l|}{$\begin{array}{l}\text { Residencia } \\
\text { (ref. urbana) }\end{array}$} \\
\hline Rural & $\begin{array}{c}-0,127^{\star \star \star} \\
(0,011)\end{array}$ & $\begin{array}{c}-0,050^{\star \star \star} \\
(0,003)\end{array}$ & $\begin{array}{c}-0,033^{\star \star \star} \\
(0,005)\end{array}$ & $\begin{array}{c}-0,127^{\star \star \star} \\
(0,012)\end{array}$ & $\begin{array}{l}-0,051^{\star \star *} \\
(0,003)\end{array}$ & $\begin{array}{c}-0,034^{\star \star \star} \\
(0,006)\end{array}$ \\
\hline \multicolumn{7}{|l|}{$\begin{array}{l}\text { Posición en el hogar } \\
\text { (ref. jefe/a) }\end{array}$} \\
\hline Cónyuge & $\begin{array}{c}-0,153^{\star \star \star} \\
(0,010)\end{array}$ & $\begin{array}{c}-0,068^{\star \star \star} \\
(0,003)\end{array}$ & $\begin{array}{c}-0,055^{\star \star \star} \\
(0,005)\end{array}$ & $\begin{array}{c}-0,154^{\star \star \star} \\
(0,011)\end{array}$ & $\begin{array}{c}-0,069^{\star \star \star} \\
(0,004)\end{array}$ & $\begin{array}{c}-0,055^{\star \star \star} \\
(0,005)\end{array}$ \\
\hline Niño/a & $\begin{array}{c}-0,293^{\star \star \star} \\
(0,017)\end{array}$ & $\begin{array}{c}-0,111^{\star \star \star} \\
(0,004)\end{array}$ & $\begin{array}{c}-0,139^{\star \star \star} \\
(0,005)\end{array}$ & $\begin{array}{c}-0,293^{\star \star \star} \\
(0,017)\end{array}$ & $\begin{array}{c}-0,111^{\star \star \star} \\
(0,004)\end{array}$ & $\begin{array}{c}-0,139^{\star \star \star} \\
(0,006)\end{array}$ \\
\hline Otro/a & $\begin{array}{c}-0,177^{\star \star \star} \\
(0,027)\end{array}$ & $\begin{array}{c}-0,108^{\star \star \star} \\
(0,005)\end{array}$ & $\begin{array}{l}-0,158^{\star \star \star} \\
(0,007)\end{array}$ & $\begin{array}{c}-0,175^{\star \star \star} \\
(0,025)\end{array}$ & $\begin{array}{c}-0,108^{\star \star \star} \\
(0,005)\end{array}$ & $\begin{array}{c}-0,157^{\star \star \star} \\
(0,007)\end{array}$ \\
\hline \multicolumn{7}{|l|}{$\begin{array}{l}\text { Situación conyugal } \\
\text { (ref. no unido/a) }\end{array}$} \\
\hline Unido/a & $\begin{array}{c}0,032^{\star \star \star} \\
(0,008)\end{array}$ & $\begin{array}{c}0,071^{\star \star \star} \\
(0,003)\end{array}$ & $\begin{array}{c}0,065^{\star \star \star} \\
(0,005)\end{array}$ & $\begin{array}{c}0,032^{\star \star \star} \\
(0,007)\end{array}$ & $\begin{array}{c}0,071^{\star \star \star} \\
(0,003)\end{array}$ & $\begin{array}{c}0,066^{\star \star \star} \\
(0,005)\end{array}$ \\
\hline $\begin{array}{l}\text { Tasa de dep. intra- } \\
\text { familiar }\end{array}$ & $\begin{array}{c}-0,039^{\star \star \star} \\
(0,007)\end{array}$ & $\begin{array}{c}-0,015^{\star \star \star} \\
(0,002)\end{array}$ & $\begin{array}{c}0,014^{\star \star \star} \\
(0,004)\end{array}$ & $\begin{array}{c}-0,039^{\star \star \star \star} \\
(0,008)\end{array}$ & $\begin{array}{c}-0,015^{\star \star \star} \\
(0,002)\end{array}$ & $\begin{array}{c}0,014^{\star \star \star} \\
(0,003)\end{array}$ \\
\hline
\end{tabular}




\begin{tabular}{|c|c|c|c|c|c|c|}
\hline & \multicolumn{3}{|c|}{ Modelo1 } & \multicolumn{3}{|c|}{ Modelo2 } \\
\hline & Q10 & Q50 & Q90 & Q10 & Q50 & Q90 \\
\hline \multicolumn{7}{|l|}{$\begin{array}{l}\text { Clase ocupacional (ref. } \\
\text { No manual alta calif.) }\end{array}$} \\
\hline $\begin{array}{r}\text { No manual baja } \\
\text { calificación. } \\
\text { Manual } \\
\text { calificada }\end{array}$ & $\begin{array}{c}-0.228^{\star \star \star} \\
(0.009) \\
-0.253^{\star \star \star} \\
(0,010) \\
-0,313^{\star \star \star}\end{array}$ & $\begin{array}{c}-0.278^{\star \star \star} \\
(0.003) \\
-0.246^{\star \star \star} \\
(0,004) \\
-0,305^{\star \star \star}\end{array}$ & $\begin{array}{c}-0.342^{\star \star \star} \\
(0.005) \\
-0.309^{\star \star \star} \\
(0,007) \\
-0,425^{\star \star \star}\end{array}$ & $\begin{array}{c}-0.228^{\star \star \star} \\
(0.009) \\
-0.253^{\star \star \star} \\
(0,011) \\
-0,314^{\star \star \star}\end{array}$ & $\begin{array}{c}-0.279^{\star \star \star} \\
(0.003) \\
-0.246^{\star \star \star} \\
(0,005) \\
-0,305^{\star \star \star}\end{array}$ & $\begin{array}{c}-0.342^{\star \star \star} \\
(0.006) \\
-0.309^{\star \star \star} \\
(0,008) \\
-0,426^{\star \star \star}\end{array}$ \\
\hline Manual no calificado & $(0,016)$ & $(0,005)$ & $(0,007)$ & $(0,019)$ & $(0,005)$ & $(0,006)$ \\
\hline & Q10 & Q50 & Q90 & Q10 & Q50 & Q90 \\
\hline \multicolumn{7}{|l|}{$\begin{array}{l}\text { Cantidad de trabajos } \\
\text { (ref. uno) }\end{array}$} \\
\hline dos y más & $\begin{array}{c}0,112^{\star \star \star} \\
(0,009)\end{array}$ & $\begin{array}{c}0,068^{\star \star \star} \\
(0,004)\end{array}$ & $\begin{array}{c}0,091^{\star \star \star} \\
(0,006)\end{array}$ & $\begin{array}{c}0,112^{\star \star \star} \\
(0,009)\end{array}$ & $\begin{array}{c}0,068^{\star \star \star} \\
(0,004)\end{array}$ & $\begin{array}{c}0,090^{\star \star \star} \\
(0,007)\end{array}$ \\
\hline \multicolumn{7}{|l|}{ Sector (ref. privado) } \\
\hline Sector público & $\begin{array}{c}0,516^{\star \star \star} \\
(0,007)\end{array}$ & $\begin{array}{c}0,206^{\star \star \star} \\
(0,003)\end{array}$ & $\begin{array}{c}0,026^{\star \star \star} \\
(0,004)\end{array}$ & $\begin{array}{c}0,516^{\star \star \star} \\
(0,007)\end{array}$ & $\begin{array}{c}0,206^{\star \star \star} \\
(0,003)\end{array}$ & $\begin{array}{c}0,026^{\star \star \star} \\
(0,005)\end{array}$ \\
\hline \multicolumn{7}{|l|}{$\begin{array}{l}\text { Año de la encuesta } \\
\text { (ref. 2013) }\end{array}$} \\
\hline 2014 & $\begin{array}{c}0,047^{\star \star \star} \\
(0,012)\end{array}$ & $\begin{array}{c}0,040^{\star \star \star} \\
(0,003)\end{array}$ & $\begin{array}{c}0,046^{\star \star *} \\
(0,006)\end{array}$ & $\begin{array}{c}0,047^{\star \star \star} \\
(0,010)\end{array}$ & $\begin{array}{c}0,040^{\star * \star} \\
(0,003)\end{array}$ & $\begin{array}{c}0,047^{\star * *} \\
(0,005)\end{array}$ \\
\hline 2015 & $\begin{array}{c}0,067^{\star \star \star} \\
(0,012)\end{array}$ & $\begin{array}{c}0,048^{\star \star *} \\
(0,004)\end{array}$ & $\begin{array}{c}0,050^{\star \star *} \\
(0,006)\end{array}$ & $\begin{array}{c}0,067^{\star \star \star} \\
(0,010)\end{array}$ & $\begin{array}{c}0,049^{\star \star \star} \\
(0,004)\end{array}$ & $\begin{array}{c}0,050^{\star \star *} \\
(0,005)\end{array}$ \\
\hline 2016 & $\begin{array}{c}0,085^{\star \star \star} \\
(0,012)\end{array}$ & $\begin{array}{c}0,054^{\star \star \star} \\
(0,004)\end{array}$ & $\begin{array}{c}0,034^{\star \star \star} \\
(0,006)\end{array}$ & $\begin{array}{c}0,085^{\star \star \star} \\
(0,012)\end{array}$ & $\begin{array}{c}0,054^{\star \star \star} \\
(0,004)\end{array}$ & $\begin{array}{c}0,034^{\star \star \star} \\
(0,005)\end{array}$ \\
\hline 2017 & $0,151^{\star \star \star}$ & $0,087^{\star \star \star}$ & $0,065^{\star \star \star}$ & $0,151^{\star \star \star}$ & $0,089^{\star \star \star}$ & $0,065^{\star \star \star}$ \\
\hline & $(0,012)$ & $(0,004)$ & $(0,006)$ & $(0,010)$ & $(0,004)$ & $(0,005)$ \\
\hline & & & & \multicolumn{3}{|c|}{$\begin{array}{l}\text { Interacciones condición migratoria y } \\
\text { ascendencia étnico racial }\end{array}$} \\
\hline Inmigrante reciente \# & & & & $0,424^{\star \star}$ & $-0,047$ & $-0,247^{\star \star}$ \\
\hline Afro & & & & $(0,211)$ & $(0,046)$ & $(0,119)$ \\
\hline Inmigrante reciente \# & & & & $0,739^{\star \star \star}$ & $-0,042$ & $-0,352^{*}$ \\
\hline Otra & & & & $(0,186)$ & $(0,056)$ & $(0,187)$ \\
\hline Inmigrante antiguo \# & & & & $-0,234$ & $-0,109^{\star}$ & $-0,067$ \\
\hline Afro & & & & $(0,245)$ & $(0,056)$ & $(0,090)$ \\
\hline Inmigrante antiguo \# & & & & $-0,171$ & $-0,053$ & $-0,191^{\star \star}$ \\
\hline Otra & & & & $(0,371)$ & $(0,048)$ & $(0,088)$ \\
\hline Constante & $\begin{array}{c}0,916^{\star \star \star} \\
(0,073)\end{array}$ & $\begin{array}{c}3,792^{\star \star \star} \\
(0,018)\end{array}$ & $\begin{array}{c}4,742^{\star \star \star} \\
(0,024)\end{array}$ & $\begin{array}{c}0,915^{\star \star \star} \\
(0,089)\end{array}$ & $\begin{array}{c}3,793^{\star \star \star} \\
(0,015)\end{array}$ & $\begin{array}{c}4,743^{\star \star \star} \\
(0,018)\end{array}$ \\
\hline Seudo R2 & 0,125 & 0,177 & 0,210 & 0,125 & 0,177 & 0,210 \\
\hline Observaciones & & 289.817 & & & 289.817 & \\
\hline
\end{tabular}

${ }^{*} p<0.10,{ }^{* \star} p<0.05,{ }^{* \star *} p<0.001$

Fuente: elaboración propia con base en microdatos de la Encuesta Continua de Hogares del 2013 al 2017. 